\title{
FOREST CANOPY HEIGHT ESTIMATION FROM CALIPSO LIDAR MEASUREMENT
}

\author{
Xiaomei Lu', Yongxiang Hu²*, Patricia L. Lucker ${ }^{1}$, Charles Trepte ${ }^{2}$ \\ ${ }^{1}$ Science Systems and Applications, Inc., Hampton, Virginia 23666, USA \\ ${ }^{2}$ NASA Langley Research Center, Hampton, VA 23681, USA, *Email: Yongxiang.hu-1@nasa.gov
}

\begin{abstract}
The canopy height is an important parameter in aboveground biomass estimation. Lidar remote sensing from airborne or satellite platforms, has a unique capability for forestry applications. This study introduces an innovative concept to estimate canopy height using CALIOP two wavelengths lidar measurements. One main advantage is that the concept proposed here is dependent on the penetration depths at two wavelengths without making assumption about the last peak of waveform as the ground location, and it does not require the ancillary Digital Elevation Model (DEM) data in order to obtain the slope information of terrain.
\end{abstract}

Canopy penetration depths at two wavelengths indicate moderately strong relationships for estimating the canopy height. Results show that the CALIOP-derived canopy heights were highly correlated with the ICESat/GLAS-derived values with a mean RMSE of $3.4 \mathrm{~m}$ and correlation coefficient (R) of 0.89 . Our findings present a relationship between the penetration difference and canopy height, which can be used as another metrics for canopy height estimation, except the full waveforms.

\section{INTRODUCTION}

Lidar remote sensing, from airborne or satellite platforms, has a unique capability for forestry applications, such as estimating forest canopy height [1], forest structural attributes [2] as well as aboveground biomass [3, 4]. Airborne small footprint full waveform lidar measurements can provide the best accuracy of canopy height, even for dense forests. However, the use of airborne lidar data is usually limited to local or regional areas. Many researchers have studied the forest canopy height globally from large footprint spaceborne lidars [3-7]. For example, the Geoscience Laser Altimeter System (GLAS) on the Ice, Cloud and land Elevation Satellite (ICESat) provides forest canopy height from the full waveform data [8-11].

The methods based on the full waveform required the exact position of the top of the canopy and ground peaks in order to better and accurately estimate the canopy height. Therefore, estimating forest canopy height from large-footprint satellite lidar full waveforms is challenging due to the complex interaction between lidar waveforms, terrain, and vegetation, especially in dense tropical and equatorial forests [5]. For example, terrain slope and roughness are the main factors contributing to canopy height estimation error, since the impact of slope and roughness is to broaden the lidar waveform, and thereby introducing a bias in canopy height estimates. In addition, as canopies become more closed, forest metrics such as waveform extent, trailing and leading edge derived from full waveforms become more difficult because laser pulse returns tend to be preferentially distributed towards the outer envelope of the tree crown, with fewer pulses penetrating past the height above ground level at which canopies become closed. Generally, for the full waveforms method, the ground can be determined as the last Gaussian peak, which works best in flat areas and open canopies. However, within closed canopies, locating the ground is sometimes difficult, for example, when the last peak has low amplitude relative to another neighboring peak [6], or few lidar returns reach the ground in tropical forests. Moreover, over very sloped terrain, laser returns from both canopy and ground surfaces can occur at the same elevation, and as a result it is difficult to estimate the tree canopy height from the full waveform methods. Lidar does have certain foliage penetration capability even for densely vegetated forests. Therefore, it can offer advantage in certain detection and identification applications.

In this paper, we used the penetration difference at two wavelengths to estimate the forest canopy 
height from space-borne lidar measurements, such as CALIOP lidar.

\section{TWO WAVELENGHT METHOD}

CALIOP, a three-channel elastic-backscatter lidar, has been operating since June 2006 and is expected to continue for several more years. Recently, a super-resolution altimetry method has been proposed to provide improved lidar altimetry from CALIOP lidar measurements [12, 13]. The precision of the altimetry products retrieved by the method is much better than $1.4 \mathrm{~m} \mathrm{[8]} \mathrm{and} \mathrm{can}$ be as good as GLAS [14]. Since the CALIOP lidar measurements are discontinuous with a footprint of about $70 \mathrm{~m}$ spaced every $333 \mathrm{~m}$ along ground track, the results from CALIOP data were averaged within $1^{\circ}$ cell.

When the laser pulse cannot penetrate the thick foliage of closed forest, the exact location of peak pulse return retrieved by the super-resolution altimetry method [12] is the laser penetration depth. The penetration difference between 1064 and $532 \mathrm{~nm}$ was shown in Fig. 1. The penetration difference is likely due to the relative larger reflectance in infrared $(>50 \%)$ than that in green $(<15 \%)$ and thus there is more probability of photons penetration through forest canopy at 532 $\mathrm{nm}$ than that at $1064 \mathrm{~nm}$. The penetration difference as shown in Fig. 1 is higher than $8 \mathrm{~m}$ in the tropical forest near Equator.

The GLAS has 1064- and 532-nm channels the longer wavelength of which is used for surface altimetry. Several canopy height models from GLAS waveforms have been developed in recent years depending on different parameters retrieved from full waveforms and ancillary DEM data [811]. The GLAS-derived canopy height within each footprint has a precision between 2 and $13 \mathrm{~m}$ depending on forest types and characteristics of the study site. The GLAS canopy height used in this paper is the waveform metric RH100, defined as the distance between signal beginning and the location of the ground peak. This product provides the top of the canopy height that can be downloaded from ORNL Distributed Active Archive Center for Biogeochemical Dynamics. The GLAS-derived canopy height was shown in Fig. 2. The linear relationship between penetration difference at two wavelengths and canopy height was shown in Fig. 3. Color code represents the number of occurrences. The fitted red line of Fig. 3 can be written as:

$$
y=7.0144 x \quad 19.5474
$$

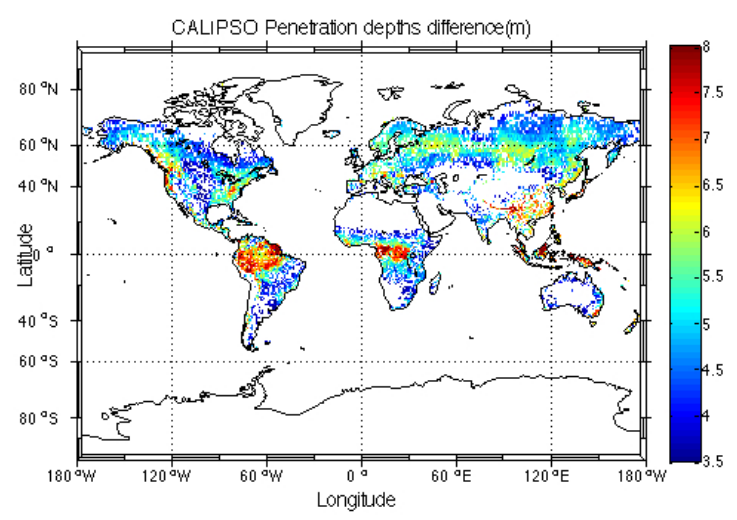

Figure 1. Global distribution $\left(1^{\circ} \times 1^{0}\right)$ of the penetration differences (meter) between 1064 and $532 \mathrm{~nm}$.

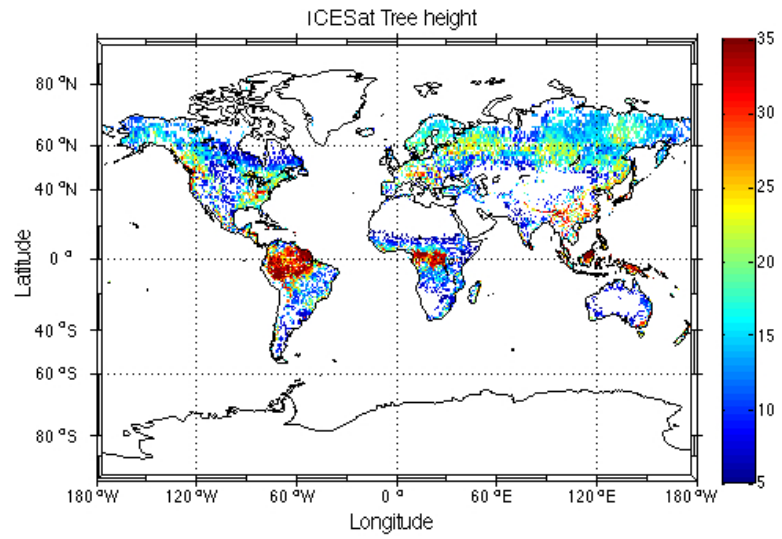

Figure 2. ICESat GLAS-derived canopy height. The unit of the height in color bar is meter.

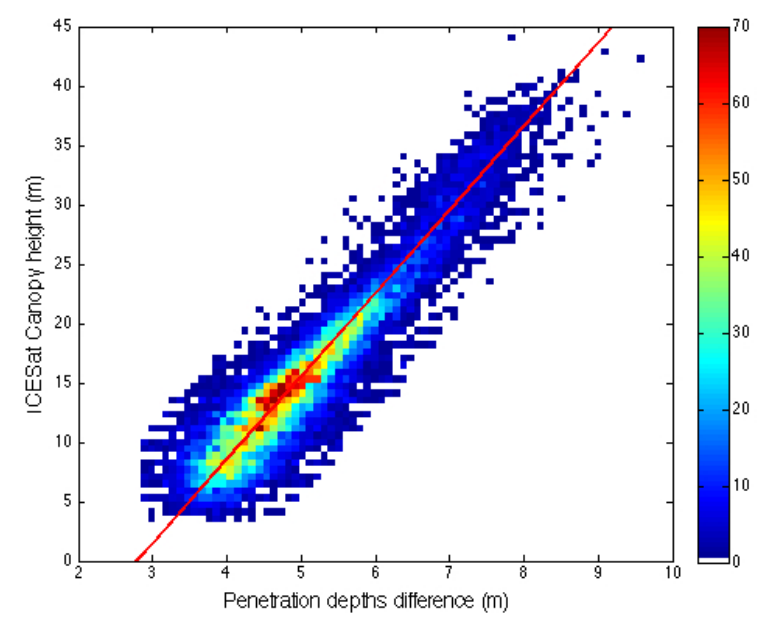

Figure 3. Relationship between penetration difference and canopy height, the red line is the 
linear fit. Color code represents the number of occurrences.

\section{RESULTS AND VALIDATION}

The locations of the peak laser return were first retrieved by the super-resolution altimetry method at wavelengths of both 1064 and $532 \mathrm{~nm}$ in order to get the penetration difference between the two wavelengths. The canopy height was finally obtained based on Equation 1. The globally distributon of CALIOP-derived canopy height was shown in Fig. 4. Figure 5 shows the difference between CALIOP-derived and GLASderived canopy height. Results of Fig. 2, 4 and 5 show that the CALIOP-derived canopy heights were highly correlated with the ICESat/GLASderived values with a mean RMSE of $3.4 \mathrm{~m}$ and correlation coefficient (R) of 0.89 .

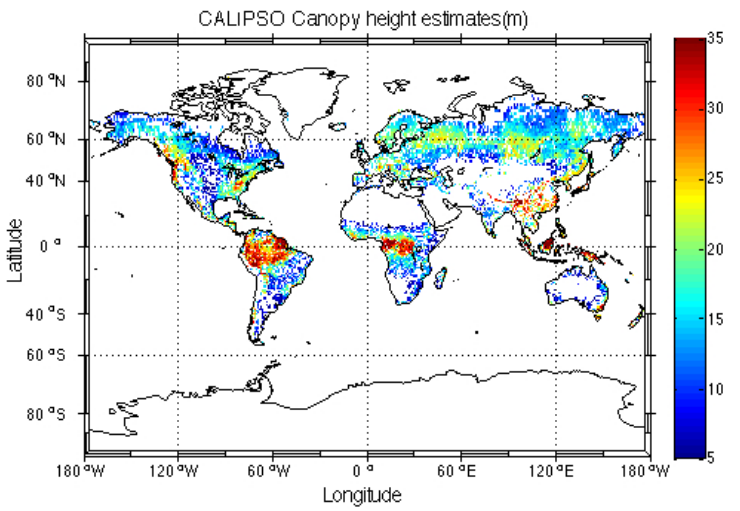

Figure 4. The CALIOP-derived canopy height (meter). The color bar represents the height.

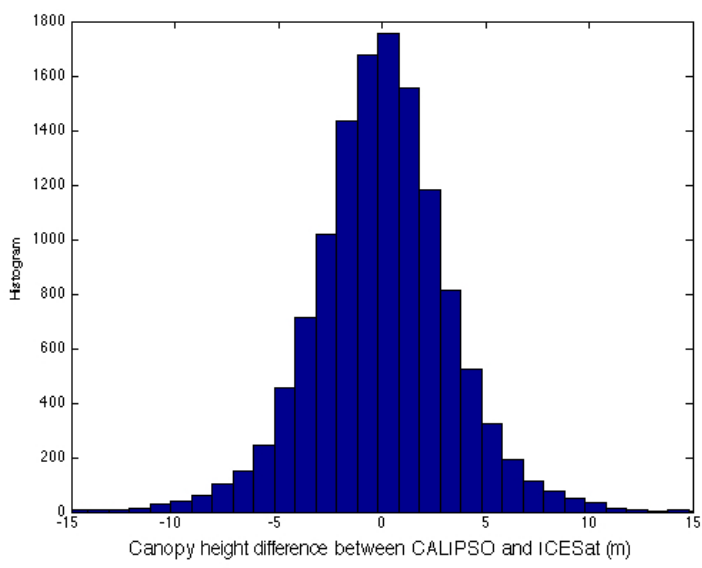

Figure 5. Canopy height difference between CALIOP and ICESat GLAS-derived ones.

NASA's Laser Vegetation Imaging Sensor (LVIS) is a scanning laser altimeter instrument that is flown by aircraft to collect data on surface topography and vegetation coverage. It was designed and developed at NASA's Goddard Space Flight Center (GSFC). LVIS operates at altitudes up to $10 \mathrm{~km}$ above ground, and is capable of producing a data swath up to $1000 \mathrm{~m}$ wide nominally with $25-\mathrm{m}$ wide footprints. It has a vertical precision of about $10 \mathrm{~cm}$. LVIS data with latitude from $36^{\circ} \mathrm{N}$ to $46^{\circ} \mathrm{N}$ and longitude from $67^{\circ} \mathrm{W}$ to $120^{\circ} \mathrm{W}$ were used here to valid the two-wavelength method. The LVIS data were averaged in the same $1^{\circ} \times 1^{\circ}$ bins.
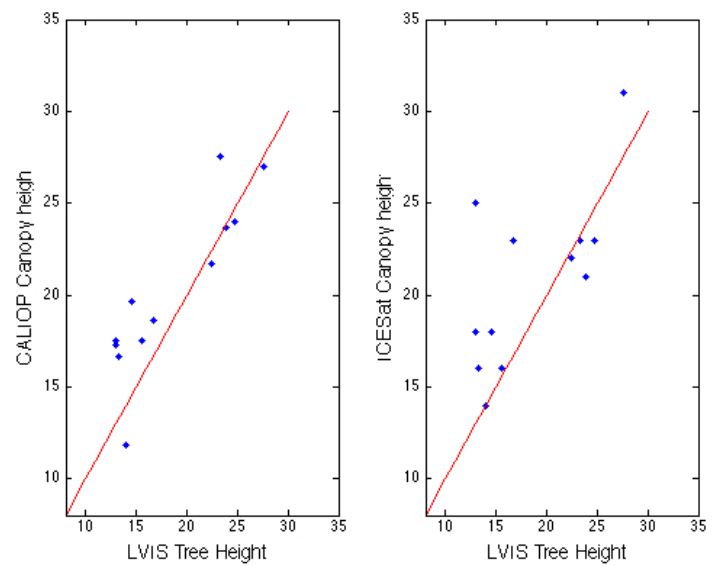

Figure 6. Canopy height (meter) comparison Left panel: CALIOP vs. LVIS; Right panel: GLAS vs. LVIS.

Figure 6 shows the canopy height comparison among CALIOP, GLAS and LVIS results. From Fig. 6, the CALIOP-derived canopy heights are in good agreement with LVIS canopy heights with standard deviation of about $2.6 \mathrm{~m}$. The standard deviation of difference between GLAS-derived canopy height and LVIS height is about $4.1 \mathrm{~m}$. Several factors may have caused the differences shown in Fig. 6, including not exactly footprint overlap, different measurement time and seasonal difference of canopy sturcutres. Future studies will focus on the CALIOP single laser shot and its co-located with in situ measurements in order to estimate canopy heigth with higher spatially resolution.

\section{CONCLUSIONS}

In this study, canopy height was estimated using CALIOP lidar measurements. This analysis was based on the different canopy penetration depths of laser pulses at wavelengths of $1064 \mathrm{~nm}$ and $532 \mathrm{~nm}$. Results show that canopy penetration 
differences at two wavelengths indicate moderately strong relationships for estimating the canopy height, and the CALIOP-derived canopy heights were highly correlated with the ICESat/GLAS-derived canopy heights and LVIS results. The proposed method provides potential use of two-wavelength lidar for vegetation canopy height studies.

Future generations of airborne dual wavelength lidar with small footprint (meters) may provide accurate canopy height with high spatial resolution. The relationship between the penetration difference at different wavelength and canopy height will lead to significantly advance in canopy height estimation, except the full waveform method.

\section{REFERENCES}

[1] M. A. Lefsky, (2010), "A global forest canopy height map from the Moderate Resolution Imaging Spectroradiometer and the Geoscience Laser Altimeter System," Geophysical Research Letters, vol. 37, p. L15401.

[2] J. B. Drake, et al. (2002), "Estimation of tropical forest structural characteristics using large-footprint lidar," Remote Sensing of Environment, vol. 79, pp. 305-319.

[3] G. Zhang, et al. (2014), "Estimation of forest aboveground biomass in California using canopy height and leaf area index estimated from satellite data," Remote Sensing of Environment, vol. 151, pp. 44-56.

[4] J. B. Drake, (2001), "Estimation of tropical forest aboveground biomass using large-footprint lidar," Doctoral Dissertation--University of Maryland, College Park, p. 184.

[5] I. Fayad, et al. (2014), "Canopy Height Estimation in French Guiana with LiDAR ICESat/GLAS Data Using Principal Component Analysis and Random Forest Regressions," Remote Sensing, vol. 6, pp. 11883-11914.

[6] M. Simard, et al. (2011), "Mapping forest canopy height globally with spaceborne lidar," Journal of Geophysical Research: Biogeosciences, vol. 116, p. G04021.

[7] J. E. Kalshoven et al. (1993), "Remote sensing of the Earth's surface with an airborne polarized laser," Geoscience and Remote Sensing, IEEE Transactions on, vol. 31, pp. 438-446.
[8] M. A. Lefsky, et al., (2007), "Revised method for forest canopy height estimation from Geoscience Laser Altimeter System waveforms," Journal of Applied Remote Sensing, vol. 1, pp. 013537-013537-18.

[9] J. A. B. Rosette, et al., (2008), "Vegetation height estimates for a mixed temperate forest using satellite laser altimetry," International Journal of Remote Sensing, vol. 29, pp. 1475-1493.

[10] N. Baghdadi, et al. (2014), "Testing Different Methods of Forest Height and Aboveground Biomass Estimations From ICESat/GLAS Data in Eucalyptus Plantations in Brazil," Selected Topics in Applied Earth Observations and Remote Sensing, IEEE Journal of, vol. 7, pp. 290-299.

[11] M. A. Lefsky, et al. (2005), "Estimates of forest canopy height and aboveground biomass using ICESat," Geophysical Research Letters, vol. 32, p. L22S02.

[12] X. Lu, et al. (2014), "A Super-Resolution Laser Altimetry Concept," Geoscience and Remote Sensing Letters, IEEE, vol. 11, pp. 298-302.

[13] Y. Hu, et al. (2007), "Elevation information in tail (EIT) technique for lidar altimetry," Opt. Express, vol. 15 , pp. $14504-14515$

[14] X. Lu et al. (2014), "Accuracy of land surface elevation from CALIPSO mission data," Optical Engineering, vol. 54, pp. 031102-031102.

[15] X. Lu, et al. (2014), "Ocean subsurface studies with the CALIPSO spaceborne lidar," Journal of Geophysical Research: Oceans, vol. 119, pp. 43054317. 